
Multidisciplinary
SCIENTIFIC JOURNAL
OF MARITIME RESEARCH

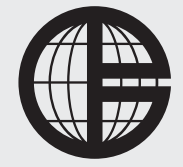
University of Rijeka
FACULTY OF MARITIME STUDIES
Multidisciplinarni
znanstveni časopis
POMORSTVO

\title{
A multi-objective integrated procurement, production, and distribution problem of supply chain network under fuzziness uncertainties
}

\author{
Kaoutar Douaioui ${ }^{1}$, Mouhsene Fri $^{2}$, Charif Mabrouki ${ }^{1}$, El Alami Semma ${ }^{1}$ \\ ${ }^{1}$ Hassan First University of Settat, Faculty of Science and Technology, Laboratory, Engineering, Industrial Management and Innovation, \\ Route de Casablanca, BP 577, Settat, Morocco, e-mail: kaoutar.douaioui@gmail.com; harif.mabrouki@uhp.ac.ma; cSemmaalam@yahoo.fr \\ ${ }^{2}$ Euromed University of Fes (UEMF), Route de Meknès, BP 30000, Fez, Morocco, e-mail: m.fri@ueuromed.org
}

\section{ABSTRACT}

In this paper, we devoted a design under uncertainty of a four-echelon supply chain network including multiple suppliers, multiple plants, multiple distributors and multiple customers. The proposed model is a bi-objective mixed integer linear programming which considers several constraints and aims to minimize the total costs including the procurement, production, storage and distribution costs as well as to maximize on-time deliveries (OTD). To bring the model closer to real-world planning problems, the objective function coefficients (e.g. procurement cost, production cost, inventory holding and transport costs) and other parameters (e.g., demand, production capacity and safety stock level), are all considered triangular fuzzy numbers. Besides, a hybrid mathematical model-based on credibility approach is constructed for the problem, i.e., expected value and chance constrained models. Moreover, to build the crisp equivalent model, we use different property of the credibility measure. The resulted crisp equivalent model is a bi-objective mixed integer linear programs (BOMILP). To transform this crisp BOMILP into a single objective mixed integer linear programs (MILP) model, we apply three different aggregation functions. Finally, numerical results are reported for a real case study to demonstrate the efficiency and applicability of the proposed model.

\section{ARTICLE INFO}

Preliminary communication

Received 2 February 2021

Accepted 8 September 2021

\section{Key words:}

Supply Chain Network

Procurement-Production-Distribution

Credibility Theory

Aggregation Functions

\section{Introduction}

Given the current trends in globalization, many companies are increasingly sourcing, producing and marketing their products around the world. For many of them, success depends on a personalized production, in a short time and at a good price. Over the past two decades, supply chain management has proven to be an unavoidable solution to meet these contradictory constraints. As a result, several researchers and practitioners focus on integrating the various supply chain functions to increase flexibility, to improve cycle times and to reduce costs. This integration not only reduces the number of steps in the process but also tends to eliminate the inherent barriers between the various functions in order to see overall optimization. Our research is in line with this trend, with the aim of studying the problem of integration of functions such as procurement, production, storage and distribution of the supply chain network. It should also be noted that the challenges associated to the variability of demand are accentuated by the length of the manufacturing period and the transport conditions. All these factors make planning and scheduling of the supply chain network a difficult task. All the problems mentioned above are often dealt with under specific conditions. According to [1], any supply chain planning that relies on deterministic conditions risks losing its durability. They also mention that in some cases, it is not enough for the company to consider usual parameters such as demand, prices or other parameters such as random variables, but undesirable events such as Cyber Security Threats and natural disasters. Therefore, it is necessary to integrate uncertainty into supply chain planning.

The main contributions of this paper can be summarized as follows: (i) introduction, in third section, of a MILP formulation for integrated procurement, production and distribution problem within the supply chain network, (ii) consideration of different sources of uncertainty such as costs, demand, production capacity and safety 
stock level, (iii) utilization, in fifth section, of the credibility theory as an appropriate framework to deal with the uncertainty, (iv) overcoming the problems related to the use single models such as expected value model or chanceconstrained model by taking the advantages of both techniques, such as the uses the expected value to cope with imprecise objective functions and the chance constrained programming approach. $(\mathrm{v})$ the use aggregate functions to handle multi-objective problem, (vi) testing the sensitivity and robustness of the proposed model in sixth section.

The rest of this paper is organized as follows. Section 2 presents a brief survey of relevant literature. Section 3 gives the structure of supply chain network, a detailed description of the problem and the mathematical formulation. Section 4 describes a brief presentation of the credibility theory, the proposed bi-objective credibility fuzzy model and the crisp equivalent model. Section 5 presents the proposed solution approaches. Section 6 provides the numerical results in order to illustrate the highlight characteristics of the proposed model and methodology. Finally, in Section 7, some conclusions and future research directions are given.

\section{Literature review}

Based on literature, the paper aims to design decision model in supply chain under uncertainty according to four groups of attributes explained in table 1: i) analysis type, ii) decision level, ii) type of information, iv) modeling of the structure. These attributes, the philosophy of decision and methods will help to position the publications and analysis approaches and thus identify the widest possible scope of scientific productions. The obtained classifications are based on relevant publications: i) ScienceDirects, ii) Emerald Insight, iii) Taylor and Francis, iv) Springer and v) IEEE.

\section{Supply Chain Network}

\subsection{Description of Supply Chain network}

This work is motivated by the problem of integrating procurement, production and distribution functions of a supply chain network which has several geographically dispersed suppliers, production sites, distribution centers (DC) and customers. Each supplier has a limited procurement capacity. Each production has a limited production time capacity which depends essentially on the installed processing units and the speed of each unit. The utilization of a production unit generates production and set-up costs that must be integrated into the model. In general, the optimization procedure must consider other costs such as holding inventory, transportation, and backorder. The model considers also the on-time delivery of the product of each customer. Figure 1 represents an illustration of the supply chain network.

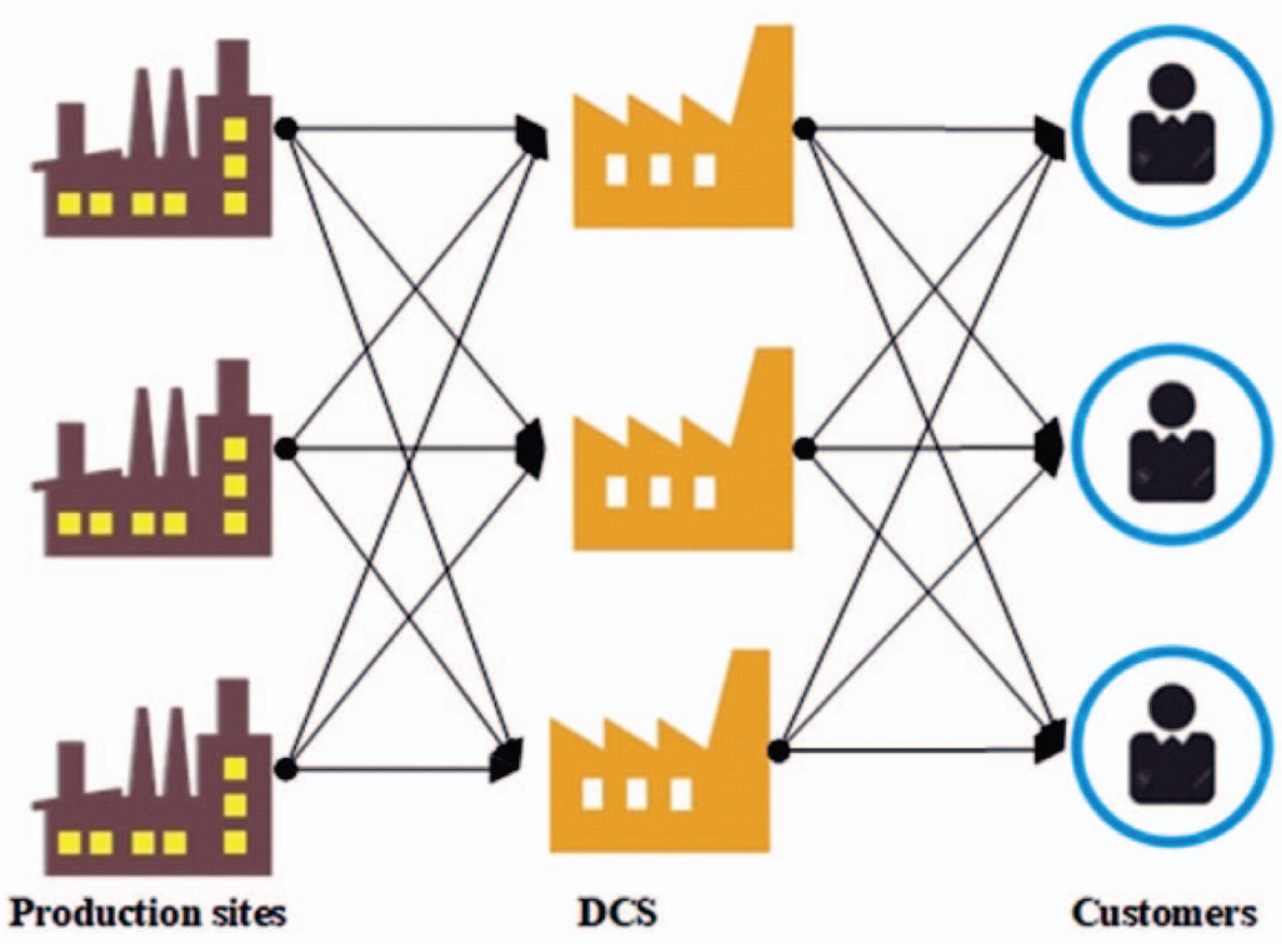

Figure 1 Supply chain network 
Table 1 Classification of publication

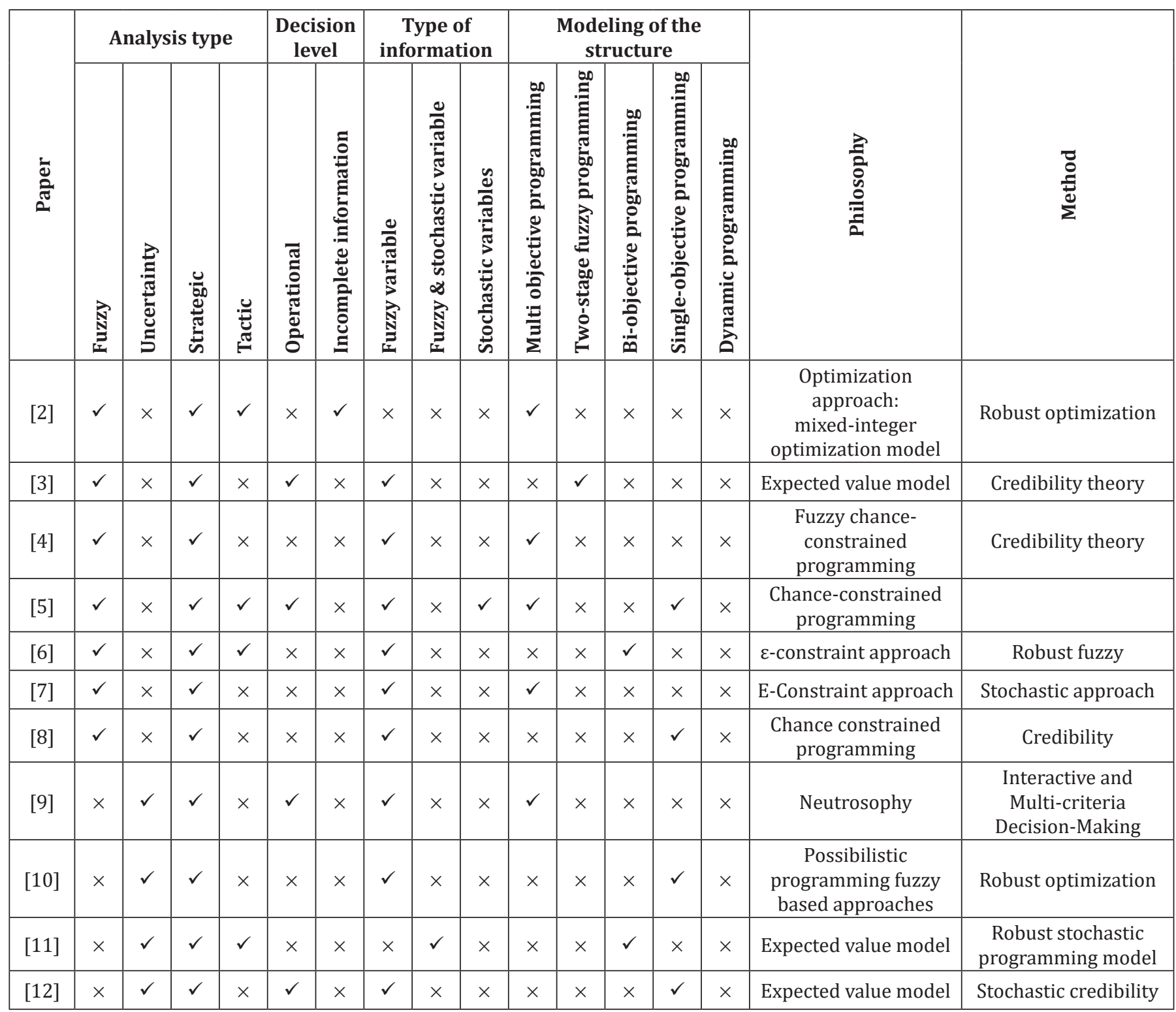

Source: Authors

\subsection{Supply chain management under uncertainty}

The theory of probability proved to be the old theory to deal with uncertain parameters. However, in practice, several disadvantages are related to the use of the probability theory (1) need for a sufficient and reliable history and (2) problem of modelling of subjective parameters [13], [14]. The fuzzy set theory (FST) is an alternative to treat uncertainty by giving local preferences into account in optimization problems.

In the fuzzy set theory, there are three types of measures for a fuzzy event namely the possibility, the necessity, and the credibility measure. Possibility theory as considered as a mathematical counterpart of probability theory [15] and widely used in literature to treat the fuzzy variables. Furthermore, it is inconsistent with the law of ex- cluded middle and the law of contradiction. For example, a fuzzy event may fail even though its possibility value is 1 and hold even though its necessity value is 0 . for the reason that possibility measure does not satisfy self-duality property which is absolutely needed in both theory and practice. To overcome this challenge, Baoding Liu and Yian-Kui Liu [16] proposed the credibility measure as a self-dual measure. The credibility measure is a more reasonable fuzzy inequality indicator than the possibility and necessity because it compensates for their disadvantages. For example, an event with maximum possibility 1 might not happen while an event with maximum credibility 1 occurs. Furthermore, a fuzzy event with maximum possibility 1 sometimes carries no information while a fuzzy event with maximum credibility 1 means that the event will happen at the greatest chance [17]. In the optimization proc- 
ess for management and planning, it is usually assumed that the credibility level should be greater than 0.5 in response to avoiding improper un-satisfactions and violated risks [18].

Let $\xi$ be a fuzzy variable with membership function $\mu(x)$, and let $t$ be a real number. Based on [16] the credibility measure is defined as follows:

$\operatorname{Cr}\{\xi \leq \mathrm{t}\}=\frac{1}{2}\left(\operatorname{Sup}_{\mathrm{x} \leq \mathrm{t}} \mu(\mathrm{x})+1-\operatorname{Sup}_{\mathrm{x}>t} \mu(\mathrm{x})\right)$

Noteworthy, since $\operatorname{Pos}\{\xi \leq t\}=\operatorname{Sup}_{x \leq t} \mu(x)$ and $\operatorname{Nec}\{\xi \leq t\}$ $=1-\operatorname{Sup}_{x>t} \mu(x)$, the credibility measure can also be defined as follows:

$\operatorname{Cr}\{\xi \leq t\}=\frac{1}{2}(\operatorname{Pos}\{\xi \leq t\}+\operatorname{Nec}\{\xi \leq t\})$

Accordingly, the credibility measure could be defined as an average of the possibility (Pos) and necessity (Nec) measures. Also, the expected value of $\xi$ can be determined based on the credibility measure as follows [16] :

$\mathrm{E}[\xi]=\int_{0}^{\infty} \operatorname{Cr}\{\xi \geq \mathrm{t}\} \mathrm{dt}-\int_{-\infty}^{0} \operatorname{Cr}\{\xi \leq \mathrm{t}\} \mathrm{dt}$

Now, let's assume that $\xi$ is a triangular fuzzy number denoted by three prominent points as $\xi=(a, b, c)$. According to the equation (3), the expected value of $E[\xi]=\frac{a+2 * b+c}{4}$ and the corresponding credibility measures are as follows:

$\operatorname{Cr}\{\xi \leq t\}=\left\{\begin{array}{cl}0, & \text { if } \mathrm{t} \leq \mathrm{a} \\ (\mathrm{t}-\mathrm{a}) / 2(\mathrm{~b}-\mathrm{a}), & \text { if } \mathrm{a}<t \leq b \\ (\mathrm{c}-2 \mathrm{~b}+\mathrm{t}) / 2(\mathrm{c}-\mathrm{b}), & \text { if } \mathrm{b}<t \leq c \\ 1, & \text { if } \mathrm{t}>c\end{array}\right.$

$\operatorname{Cr}\{\xi \geq t\}=\left\{\begin{array}{cl}1, & \text { if } \mathrm{t} \leq \mathrm{a} \\ (2 \mathrm{~b}-\mathrm{a}-\mathrm{t}) / 2(\mathrm{~b}-\mathrm{a}), & \text { if } \mathrm{a}<t \leq b \\ (\mathrm{c}-\mathrm{t}) / 2(\mathrm{c}-\mathrm{b}), & \text { if } \mathrm{b}<t \leq c \\ 0, & \text { if } \mathrm{t}>c\end{array}\right.$

Based on (4) and (5), it can be proven[19] that if $\xi$ is a triangular fuzzy number and $\beta>0.5$ then:

$\operatorname{Cr}\{\xi \leq \mathrm{t}\} \geq \beta \Leftrightarrow(2 \beta-1) \mathrm{c}+(2-2 \beta) \mathrm{b}$

$\operatorname{Cr}\{\xi \geq \mathrm{t}\} \geq \beta \Leftrightarrow(2 \beta-1) \mathrm{a}+(2-2 \beta) \mathrm{b}$

Equations (6) and (7) can be applied directly and more conveniently when compared to a-critical values proposed by [14], to convert fuzzy chance constraints into their equivalent crisp ones.

In credibility programming, there are three types of credibility-based fuzzy mathematical programming approaches: the chance-constrained programming [20], the expected value [16], and the dependent chance-con- strained programming [21]. The first model uses the expected value operator for each imprecise coefficient in the objective function and constraints. It can be applied easily without increasing the complexity of the original model compared to the other two methods, but at the same time, it has no control over the level of confidence of the fuzzy chance constraint. The second model is able to control the level of satisfaction of the fuzzy chance constraint by using the concept of $\alpha$-level, but also increases the complexity of the model since it adds a new constraint for each objective function of the main model. The third model is similar to the second in some way, but it provides a more conservative decision for the decision maker, as it gives more importance to maximizing levels of satisfaction.

In this paper, we combined the expected value operator and the chance constraint to deal with the uncertain parameters of the objective functions and constraints. The reason for this combination is that the expected value operator does not need any additional information for objective function such as confidence level or the ideal solution and is also benefited from advantages of the chance constrained programming approach in order to control the level of satisfaction of the fuzzy chance constraint by using the concept of $\alpha$-level [18].

\subsection{Mathematical formulation}

The basic considerations of the problem under consideration are summarized, as follows:

- The planning horizon is known and divided into a set of periods $t \in T$.

- A set of suppliers $s \in S$, production sites $p \in P$, a set of DCs $d \in D$, a set of customers $c \in C$, and a set of products $k \in K$.

The key decision variables are:

- The set-up of products to units in each period $t$.

- The quantity produced of each product on each processing unit at each period $t$.

- The total quantity dispatched between production sites-DCs and between DCs-Customers respectively.

- The inventory levels of each product at sites and DCs at the end of each period.

- The backorder quantity of each product p provided by the customer at each period.

\subsubsection{Indices and Sets}

s: Index used for a supplier $s=1, \ldots, S$.

r: Index used for a raw material $r=1, \ldots, R$.

p: Index used for a plant $p=1, \ldots, P$.

$\mathrm{k}$ : Index used for a finished product $k=1, \ldots, K$.

$\mathrm{d}$ : Index used for a distribution center (DC) $d=1, \ldots, D$.

c: Index used for a customer $c=1, \ldots, C$.

$\mathrm{t}$ : Index used for a planning period $t=1, \ldots, T$. 


\subsubsection{Parameters}

$\overline{\text { Scap }_{\mathrm{r}, \mathrm{s}, \mathrm{t}}}$ Fuzzy capacity of supplier s for providing raw material $r$ in period $t$.

$\overline{\mathrm{DC}_{\mathrm{k}, \mathrm{c}, \mathrm{t}}}$ Fuzzy demand of product $k$ required by customer $c$ in period $t$;

$\overline{\eta_{\mathrm{k}, \mathrm{d}, \mathrm{c}, \mathrm{t}}}$ Fuzzy on-time delivery rate of raw material $r$ offered by supplier $s$ to plant $p$ in periods time $t$.

$\overline{\mathrm{BOC}_{\mathrm{k}, \mathrm{p}, \mathrm{t}}}$ Fuzzy backorder cost per unit of product $p$ at customer $c$ in period $t$;

$\overline{\text { CIRPr }_{\text {p.t. }}}$ Fuzzy inventory holding costs for raw material $r$ in plant $p$ in period $t$

$\overline{\mathrm{CIKP}_{\mathrm{k}, \mathrm{p}, \mathrm{t}}}$ Fuzzy inventory holding cost for product $k$ in plant $p$ in period $t$;

$\overline{\mathrm{CIKD}_{\mathrm{k}, \mathrm{d}, \mathrm{t}}}$ Fuzzy inventory holding costs for product $k$ in DC $d$ in period $t$;

$\pi_{\mathrm{k}}$ Volume of products.

$\pi_{\mathrm{r}}$ Volume of raw material.

$\overline{\mathrm{pt}_{\mathrm{k}, \mathrm{p}, \mathrm{t}}}$ Fuzzy production time for product $k$ of plant $p$ in period $t$;

$\overline{\mathrm{st}_{\mathrm{k}, \mathrm{p}, \mathrm{t}}}$ Fuzzy set-up time for product $k$ of plant $p$ in period $t$;

$\overline{\mathrm{TT}_{\mathrm{p}, \mathrm{t}}}$ Fuzzy maximal available time in plant $p$ at time period $t$;

$\overline{\mathrm{CKP}_{\mathrm{k}, \mathrm{p}, \mathrm{t}}}$ Fuzzy production cost for product $k$ of plant $p$ in period $t$;

$\overline{\mathrm{CKS}_{\mathrm{k}, \mathrm{p}, \mathrm{t}}}$ Fuzzy set-up cost for product $k$ of plant $p$ in period $t$;

$\overline{\text { TCSP }_{\mathrm{r}, \mathrm{p}, \mathrm{t}}}$ Fuzzy cost for transferring raw material from supplier $s$ to plant $p$ in period $t$;

$\overline{\mathrm{TCPD}_{\mathrm{r}, \mathrm{s}, \mathrm{p}, \mathrm{t}}}$ Fuzzy cost for transferring finished product from plant $p$ to DC $d$ in period $t$;

$\overline{\mathrm{TCDC}_{\mathrm{r}, \mathrm{s}, \mathrm{t}}}$ Fuzzy costs for transferring finished products from DC $d$ to customer $c$ in period $t$;

$\overline{\text { PRcap }_{\mathrm{r}, \mathrm{p}, \mathrm{t}}}$ Fuzzy capacity of storage of warehouse plant $p$ related to raw material in period $t$.

$\overline{\text { PKcap }_{\mathrm{p}, \mathrm{t}}}$ Fuzzy capacity of storage of warehouse plant $p$ related to finished product in period $t$.

$\overline{\text { DKcap }_{\mathrm{p}, \mathrm{t}}}$ Capacity of storage of warehouse DC $d$ related to finished product in period $t$.

$\overline{\lambda_{\mathrm{k}, \mathrm{d}, \mathrm{c}, \mathrm{t}}}$ Fuzzy on-time delivery rate of product $k$ offered by distribution center $d$ to customer $c$ in period time $t$.

$\mathrm{T}_{\mathrm{k}, \mathrm{c}, \mathrm{t}}^{\mathrm{acc}}$ Minimum acceptable on-time delivery rate of customer $c$ for product $k$ in period $t$.

$\beta_{\mathrm{k}, \mathrm{c}, \mathrm{t}}$ Fuzzy maximum backlogging quantity permitted of product $k$ of customer $c$ in period $t$.

\subsubsection{Decision Variables}

$\mathrm{X}_{\mathrm{k}, \mathrm{p}, \mathrm{t}}$ 1-if product $k$ is produced by plant $p$ in period $t$.

$\operatorname{IRP}_{\mathrm{r}, \mathrm{p}, \mathrm{t}}$ Inventory level of product $r$ in plant $p$ at the end of period $t$.
$\mathrm{IKP}_{\mathrm{k}, \mathrm{t}, \mathrm{t}}$ Inventory level of product $k$ in plant $p$ at the end of period $t$.

$\mathrm{IKD}_{\mathrm{k}, \mathrm{d}, \mathrm{t}}$ Inventory level of product $k$ in DC $d$ at the end of period $t$.

$\mathrm{QRSP}_{\mathrm{r}, \mathrm{s}, \mathrm{t}}$ Quantity of raw material $r m$ dispatched from supplier $s$ to plant $\mathrm{p}$ in period $t$.

$\mathrm{QKP}_{\mathrm{k}, \mathrm{p}, \mathrm{t}}$ Quantity of finished product $k$ produced in plant $p$ in period $t$.

$\mathrm{QKPD}_{\mathrm{k}, \mathrm{d}, \mathrm{d}, \mathrm{t}}$ Quantity of finished product $k$ dispatched from plant $p$ to DC $d$ in period $t$.

$\mathrm{QKDC}_{\mathrm{rsp}, \mathrm{t}}$ Quantity of finished product $k$ dispatched from DC $d$ to customer $c$ in period $t$.

$\mathrm{BQKC}_{\mathrm{k}, \mathrm{c}, \mathrm{t}}$ Quantity of backorder for product $k$ incurred by customer $c$ in period $t$.

\subsubsection{Objective functions}

We consider two important objectives in our supply chain network problem:

1) Minimization of total cost of logistics (TC)

2) The maximization of on-time deliveries of raw materials.

The first objective function (OF1) is to minimize TC, which is commonly used as a major system-wide performance criterion in the classical supply chain network literature; where a single objective is considered. The goal is to reduce the important components of the supply chain operating costs and achieve a better utilization of resources. It consists mainly of the total costs such as:

(i) Procurement costs,

(ii) Production costs,

(iii) Inventory costs,

(iv) Transportation costs, and

(v) Backorder costs.

The second objective function (OF2) concerns the maximization of OTD. The OTD is considered to evaluate the impact of the supply-side on-time deliveries in order to ensure a continuous flow of production and minimize line stoppages in plants due to unavailability of raw materials items.

In this paper, we have assumed that the demands, supplier capacity and all units' costs (i.e. production, transportation, storage and backorder are all fuzzy variables. So, the total costs and the on-time deliveries of raw materials are also fuzzy variables. In the process of finding the optimal plan, it is meaningless to minimize the total costs as well as maximize the on-time deliveries of raw materials since we cannot rank fuzzy variables directly. In order to optimize the objective functions, it is inevitable to rank uncertain variables according to some decision criteria. Generally speaking, there exist many kinds of decision criteria to rank the fuzzy variables: one is the expected value criterion. Based on these decision criteria, we construct a new model for the supply chain network within the framework of credibility theory. One is the expected value programming model given as follows: 


$$
\begin{aligned}
& \operatorname{Min} \mathbf{O F}_{\mathbf{1}}=\sum_{\mathbf{r} \in \mathbf{R}} \sum_{\mathbf{s} \in \mathbf{S}} \sum_{\mathbf{p} \in \mathbf{P}} \sum_{\mathbf{t} \in \mathbf{T}} \mathbf{E}\left[\overline{\mathbf{T C S P}_{\mathbf{r}, \mathbf{s}, \mathbf{p}, \mathrm{t}}}\right] * \mathbf{Q R S P}_{\mathbf{r}, \mathbf{s}, \mathbf{p}, \mathrm{t}}+\sum_{\mathbf{r} \in \mathbf{R}} \sum_{\mathbf{p} \in \mathbf{P}} \sum_{\mathbf{t} \in \mathbf{T}} \mathbf{E}\left[\overline{\mathbf{C I R P}_{\mathbf{r}, \mathbf{p}, \mathrm{t}}}\right] * \mathbf{I R P}_{\mathbf{r}, \mathbf{p}, \mathrm{t}} \\
& +\sum_{\mathbf{k} \in \mathbf{K}} \sum_{\mathbf{p} \in \mathbf{P}} \sum_{\mathbf{t} \in \mathbf{T}} \mathbf{E}\left[\overline{\mathbf{C I K P}_{\mathbf{k}, \mathbf{p}, \mathbf{t}}}\right] * \mathbf{I K P}_{\mathbf{k}, \mathbf{p}, \mathbf{t}}+\sum_{\mathbf{k} \in \mathbf{K}} \sum_{\mathbf{p} \in \mathbf{P}} \sum_{\mathbf{t} \in \mathbf{T}} \mathbf{E}\left[\overline{\mathbf{C I K P}_{\mathbf{k}, \mathbf{p}, \mathbf{t}}}\right] * \mathbf{I K P}_{\mathbf{k}, \mathbf{p}, \mathbf{t}} \\
& ++\sum_{\mathbf{k} \in \mathbf{K}} \sum_{\mathbf{p} \in \mathbf{P}} \sum_{\mathbf{t} \in \mathbf{T}} \mathbf{E}\left[\overline{\mathbf{C K P}_{\mathbf{k}, \mathbf{p}, \mathbf{t}}}\right] * \mathbf{Q K \mathbf { P } _ { \mathbf { k } , \mathbf { p } , \mathbf { t } }}+\sum_{\mathbf{k} \in \mathbf{K}} \sum_{\mathbf{d} \in \mathbf{D}} \sum_{\mathbf{t} \in \mathbf{T}} \mathbf{E}\left[\overline{\mathbf{C K S}_{\mathbf{k}, \mathbf{d}, \mathbf{t}}}\right] * \mathbf{X}_{\mathbf{k}, \mathbf{d}, \mathbf{t}} \\
& +\sum_{\mathbf{k} \in \mathrm{K}} \sum_{\mathbf{p} \in \mathbf{P}} \sum_{\mathbf{d} \in \mathbf{D}} \sum_{\mathbf{t} \in \mathbf{T}} \mathbf{E}\left[\overline{\mathbf{T C P D}_{\mathbf{k}, \mathbf{p}, \mathbf{d}, \mathbf{t}}}\right] * \mathbf{Q K P D}_{\mathbf{k}, \mathbf{p}, \mathbf{d}, \mathbf{t}} \\
& +\sum_{\mathbf{k} \in \mathbf{K}} \sum_{\mathbf{d} \in \mathbf{D}} \sum_{\mathbf{c} \in \mathbf{C}} \sum_{\mathbf{t} \in \mathbf{T}} \mathbf{E}\left[\overline{\mathbf{T C D C}_{\mathbf{k}, \mathbf{d}, \mathbf{c}, \mathbf{t}}}\right] * \mathbf{Q K D C}_{\mathbf{k}, \mathbf{d}, \mathbf{c}, \mathbf{t}} \\
& +\sum_{\mathbf{k} \in \mathbf{K}} \sum_{\mathbf{c} \in \mathbf{C}} \sum_{\mathbf{t} \in \mathbf{T}} \mathbf{E}\left[\overline{\mathbf{B O C}_{\mathbf{k}, \mathbf{c}, \mathbf{t}}}\right] * \mathbf{B Q K C}_{\mathbf{k}, \mathbf{c}, \mathbf{t}}
\end{aligned}
$$

$\operatorname{Max} \mathbf{O F}_{2}=\sum_{\mathbf{r} \in \mathbf{R}} \sum_{\mathbf{s} \in \mathbf{S}} \sum_{\mathbf{p} \in \mathbf{P}} \sum_{\mathbf{t} \in \mathbf{T}} \mathbf{E}\left[\overline{\mathbf{\eta}_{\mathbf{k}, \mathbf{d}, \mathbf{c}, \mathbf{t}}}\right] * \mathbf{Q R S P}_{\mathbf{r}, \mathbf{s}, \mathbf{p}, \mathbf{t}}$

\subsubsection{Constraints}

$\operatorname{Cr}\left\{\sum_{\mathrm{r} \in \mathrm{R}} \mathrm{QRSP}_{\mathrm{r}, \mathrm{s}, \mathrm{p}, \mathrm{t}} \leq \overline{\operatorname{Scap}_{r, s, t}}\right\} \geq \theta ; \forall r \in R, s \in S, t \in T$

$\mathrm{IRP}_{\mathrm{r}, \mathrm{p}, \mathrm{t}}=\mathrm{IRP}_{\mathrm{r}, \mathrm{p}, \mathrm{t}-1}+\sum_{\mathrm{s} \in \mathrm{S}} \mathrm{QRSP}_{\mathrm{r}, \mathrm{s}, \mathrm{p}, \mathrm{t}}-\sum_{\mathrm{k} \in \mathrm{K}} \alpha_{r, k} * \mathrm{QKP}_{k, \mathrm{p}, \mathrm{t}} ; \forall r \in R, p \in P, t \in T$

$\mathrm{IKP}_{k, \mathrm{p}, \mathrm{t}}=\mathrm{IKP}_{k, \mathrm{p}, \mathrm{t}-1}+\mathrm{QKP}_{k, \mathrm{p}, \mathrm{t}}-\sum_{\mathrm{d} \in \mathrm{D}} \mathrm{QKD}_{k, \mathrm{p}, \mathrm{d}, \mathrm{t}} ; \forall k \in K, p \in P, t \in T$

$\mathrm{IKD}_{k, \mathrm{~d}, \mathrm{t}}=\mathrm{IRP}_{k, \mathrm{~d}, \mathrm{t}-1}+\sum_{\mathrm{p} \in \mathrm{P}} \mathrm{QKD}_{k, \mathrm{p}, \mathrm{d}, \mathrm{t}}-\sum_{\mathrm{c} \in \mathrm{C}} \mathrm{QKC}_{k, \mathrm{~d}, \mathrm{c}, \mathrm{t}} ; \forall k \in K, d \in D, t \in T$

$\operatorname{Cr}\left\{\sum_{\mathrm{k} \in \mathrm{K}} \overline{p t_{k, p}} * \mathrm{QKP}_{k, \mathrm{p}, \mathrm{t}}+\sum_{\mathrm{k} \in \mathrm{K}} \overline{s t_{k, p}} * X_{k, \mathrm{p}, \mathrm{t}} \leq \overline{T T_{k, p}}\right\} \geq \theta ; \forall k \in K, p \in P$

$\sum_{s \in S} \sum_{\mathrm{r} \in \mathrm{R}} \pi_{\mathrm{r}} * \mathrm{QRSP}_{r, s, p, t}+\sum_{\mathrm{r} \in \mathrm{R}} \pi_{\mathrm{r}} * \mathrm{IRP}_{r, p, t} \leq \operatorname{PRcap}_{p, t} ; \forall d \in D, t \in T$

$\sum_{\mathrm{k} \in \mathrm{K}} V_{k} * \mathrm{IKP}_{k, \mathrm{p}, \mathrm{d}, \mathrm{t}} \leq \operatorname{PKcap}_{p, \mathrm{t}} ; \forall p \in P, t \in T$

$\sum_{p \in P} \sum_{\mathrm{k} \in \mathrm{K}} V_{k} * \mathrm{QKD}_{k, \mathrm{p}, \mathrm{d}, \mathrm{t}}+\sum_{\mathrm{k} \in \mathrm{K}} V_{k} * \mathrm{IKD}_{k, \mathrm{~d}, \mathrm{t}} \leq \operatorname{DKcap}_{d, \mathrm{t}} ; \forall d \in D, t \in T$

$\mathrm{BQKC}_{\mathrm{k}, \mathrm{c}, \mathrm{t}}=\mathrm{BQKC}_{\mathrm{k}, \mathrm{c}, \mathrm{t}-1}+E\left[\overline{\mathrm{DC}_{\mathrm{k}, \mathrm{c}, \mathrm{t}}}\right]-\sum_{\mathrm{c} \in \mathrm{C}} \mathrm{QKC}_{k, \mathrm{~d}, \mathrm{c}, \mathrm{t}} ; \forall k \in K, c \in C, t \in T$

$\operatorname{Cr}\left\{\sum_{\mathrm{c} \in \mathrm{C}} \mathrm{QKC}_{k, \mathrm{~d}, \mathrm{c}, \mathrm{t}}-\mathrm{BQKC}_{\mathrm{k}, \mathrm{c}, \mathrm{T}-1} \leq \overline{\mathrm{DC}_{\mathrm{k}, \mathrm{c}, \mathrm{t}}}\right\} \geq \theta ; \forall k \in K, c \in C, t \in T$

$\operatorname{Cr}\left\{\sum_{\mathrm{c} \in \mathrm{C}} \mathrm{QKC}_{k, \mathrm{~d}, \mathrm{c}, \mathrm{t}} \leq \overline{\mathrm{DC}_{\mathrm{k}, \mathrm{c}, \mathrm{t}}}\right\} \geq \theta ; \forall k \in K, c \in C, t \in T$

$\operatorname{Cr}\left\{\mathrm{BQKC}_{\mathrm{k}, \mathrm{c}, \mathrm{t}} \leq \beta_{\mathrm{k}, \mathrm{c}, \mathrm{t}} * \overline{\mathrm{DC}_{\mathrm{k}, \mathrm{c}, \mathrm{t}}}\right\} \geq \theta ; \forall k \in K, c \in C, t \in T$

$\operatorname{Cr}\left\{\sum_{\mathrm{c} \in \mathrm{C}}\left(1-\overline{\lambda_{\mathrm{k}, \mathrm{d}, \mathrm{c}, \mathrm{t}}}\right) * \mathrm{QKC}_{k, \mathrm{~d}, \mathrm{c}, \mathrm{t}} \leq\left(1-\mathrm{T}_{\mathrm{k}, \mathrm{c}, \mathrm{t}}^{\mathrm{acc}}\right) * \overline{\mathrm{DC}_{\mathrm{k}, \mathrm{c}, \mathrm{t}}}\right\} \geq \theta ; \forall k \in K, c \in C, t \in T$

$\mathrm{X}_{\mathrm{k}, \mathrm{p}, \mathrm{t}} \in\{0,1\} ; \operatorname{IRP}_{\mathrm{r}, \mathrm{p}, \mathrm{t}} ; \operatorname{IKP}_{\mathrm{k}, \mathrm{p}, \mathrm{t}} ; \operatorname{IKD}_{\mathrm{k}, \mathrm{d}, \mathrm{t}} ; \mathrm{QRSP}_{\mathrm{r}, \mathrm{s}, \mathrm{p}, \mathrm{t}} ; \mathrm{QKP}_{\mathrm{k}, \mathrm{p}, \mathrm{t}} ; \mathrm{QKPD}_{\mathrm{k}, \mathrm{p}, \mathrm{d}, \mathrm{t}} ; \mathrm{QKDC}_{\mathrm{r}, \mathrm{s}, \mathrm{p}, \mathrm{t}} ; \mathrm{BQKC}_{\mathrm{k}, \mathrm{c}, \mathrm{t}} \geq 0$ 
Constraint 8 shows that the total raw materials transported from each available supplier to the manufacturers cannot exceed the fuzzy supplier capacity with the predetermined confidence level $\alpha$. Constraints (9-10) give the inventory balance equations of raw materials and finished products in plants respectively. Constraint 11 ensures the inventory balance equations of finished products in DCs. Constraint 12 guarantees that the fuzzy total required time to produce the products cannot exceed the total available fuzzy time with the predetermined confidence level $\alpha$. Constraint 13 shows the quantity of the raw material shipped to plant $p$ from suppliers plus the inventory level of raw material in plant $p$ in period $t$ is limited to the capacity of plant. Constraint 14 states that the production volume must be less than or equal to the total storage capacity of the plant $p$ in time period $t$. Constraint 15 shows the quantity of the product shipped to DC $\mathrm{d}$ from plant plus the inventory level of product $k$ in DC $d$ in period $t$ is limited to the capacity of DC. Constraint 16 represents that the backlog level at the end of period $t$ equal to backlog level of previous period plus the expected value of the demand minus the total received from DCs. Constraint 17 is concerned with the backlog balance equation at the last time period with the predetermined confidence level $\alpha$. Constraint 18 guarantees that the quantity of a product dispatched to each customer in a period cannot exceed their demand with the predetermined confidence level $\alpha$. Constraint 19 guarantees that the backorder quantities of product $k$ in the distribution center $d$ in time period $t$ is limited to a percentage of the demand of that period with the predetermined confidence level $\alpha$. Constraint 20 guarantees that the on-time delivery of finished products from DCs to customer $c$ with the predetermined confidence level $\alpha$. Constraint 21 defines the status of the decision variables.

\subsection{Crisp equivalent model}

To solve the proposed fuzzy model, it has become evident to transform the fuzzy chance constraints to their crisp equivalents with respect to the predetermined confidence level, and then solve the equivalent crisp model [22]. In this paper, the uncertain parameters are represented by triangular fuzzy numbers. So far, the crisp equivalents of the expected value of objective functions and the fuzzy constraints are given based on the property of the triangular fuzzy numbers, then the constraints (8), (12) and (16-20) can be deduced below as given in (8'), (12') and (16-20)'.

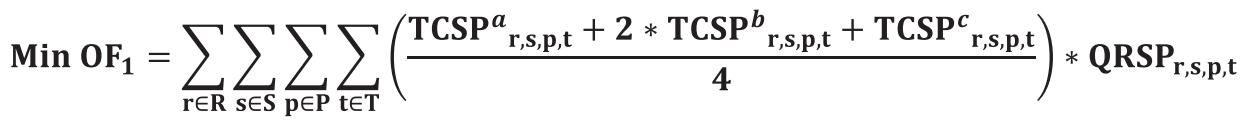

$$
\begin{aligned}
& +\sum_{\mathrm{r} \in \mathrm{R}} \sum_{\mathrm{p} \in \mathbf{P}} \sum_{\mathrm{t} \in \mathrm{T}}\left(\frac{\operatorname{CIRP}_{\mathrm{r}, \mathrm{p}, \mathrm{t}}^{a}+2 * \operatorname{CIRP}_{\mathrm{r}, \mathrm{p}, \mathrm{t}}^{b}+\operatorname{CIRP}_{\mathrm{r}, \mathrm{p}, \mathrm{t}}^{c}}{4}\right) * \operatorname{IRP}_{\mathrm{r}, \mathrm{p}, \mathrm{t}}
\end{aligned}
$$

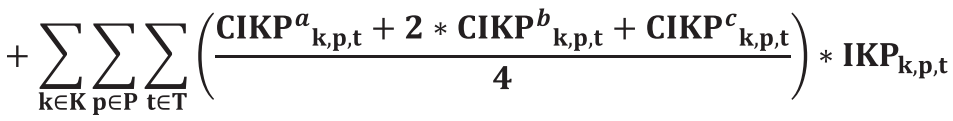

$$
\begin{aligned}
& +\sum_{\mathrm{k} \in \mathrm{K}} \sum_{\mathrm{p} \in \mathrm{P}} \sum_{\mathrm{t} \in \mathrm{T}}\left(\frac{\mathrm{CKP}_{\mathrm{k}, \mathrm{p}, \mathrm{t}}^{a}+2 * \operatorname{CIKP}_{\mathrm{k}, \mathrm{p}, \mathrm{t}}^{b}+\operatorname{CIKP}_{\mathrm{k}, \mathrm{p}, \mathrm{t}}^{c}}{4}\right) * \mathbf{Q K P}_{\mathrm{k}, \mathrm{p}, \mathrm{t}}
\end{aligned}
$$

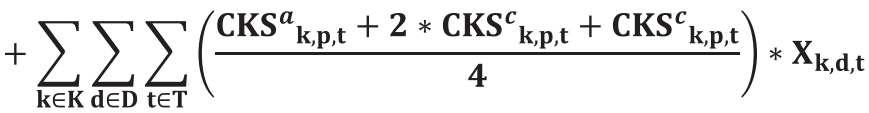

$$
\begin{aligned}
& +\sum_{\mathbf{k} \in \mathrm{K}} \sum_{\mathbf{p} \in \mathbf{P}} \sum_{\mathbf{d} \in \mathbf{D}} \sum_{\mathbf{t} \in \mathbf{T}}\left(\frac{\mathbf{T C P D}^{a}{ }_{\mathbf{k}, \mathbf{p}, \mathrm{d}, \mathrm{t}}+2 * \mathbf{T C P D}^{b}{ }_{\mathbf{k}, \mathbf{p}, \mathrm{d}, \mathrm{t}}+\mathbf{T C P D}_{\mathbf{k}, \mathbf{p}, \mathrm{d}, \mathrm{t}}}{4}\right) * \mathbf{Q K P D}_{\mathbf{k}, \mathbf{p}, \mathrm{d}, \mathrm{t}} \\
& +\sum_{\mathbf{k} \in \mathbf{K}} \sum_{\mathbf{d} \in \mathbf{D}} \sum_{\mathbf{c} \in \mathbf{C}} \sum_{\mathbf{t} \in \mathbf{T}}\left(\frac{\operatorname{TCDC}_{\mathbf{k}, \mathbf{d}, \mathbf{c}, \mathbf{t}}+2 * \mathbf{T C D C}_{\mathbf{k}, \mathbf{d}, \mathbf{c}, \mathbf{t}}+\mathbf{T C D C}^{c}{ }_{\mathbf{k}, \mathbf{d}, \mathbf{c}, \mathbf{t}}}{4}\right) * \mathbf{Q K D C}_{\mathbf{k}, \mathbf{d}, \mathbf{c}, \mathbf{t}} \\
& +\sum_{\mathbf{k} \in \mathrm{K}} \sum_{\mathbf{c} \in \mathrm{C}} \sum_{\mathbf{t} \in \mathrm{T}}\left(\frac{\mathrm{BOC}_{\mathbf{k}, \mathbf{c}, \mathbf{t}}^{a}+2 * \mathrm{BOC}_{\mathbf{k}, \mathbf{c}, \mathbf{t}}+\mathrm{BOC}^{c}{ }_{\mathbf{k}, \mathbf{c}, \mathbf{t}}}{4}\right) * \mathrm{BQKC}_{\mathbf{k}, \mathbf{c}, \mathbf{t}}
\end{aligned}
$$

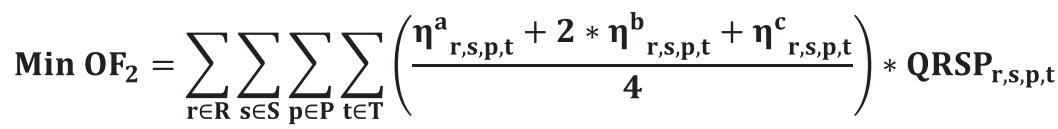




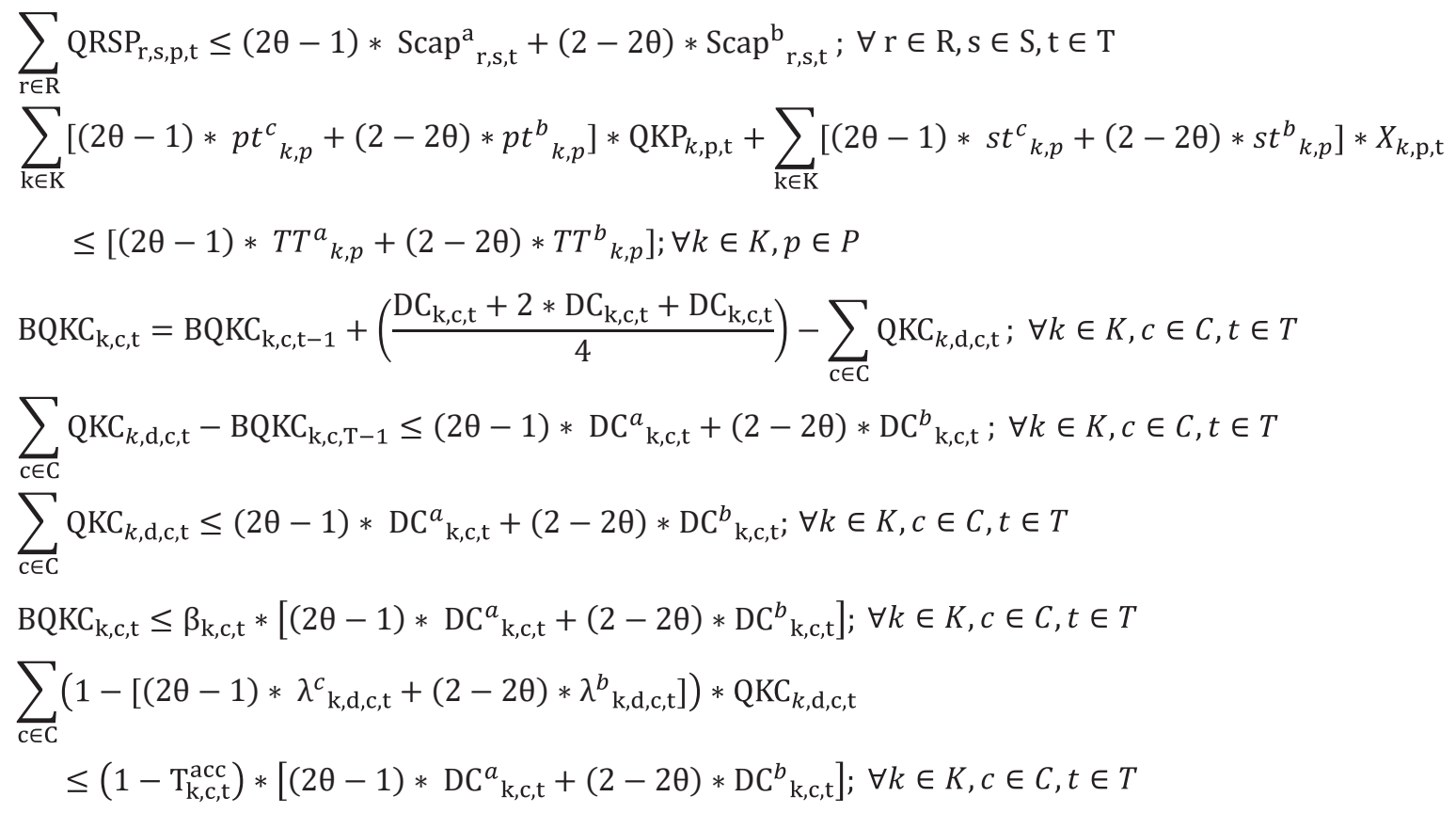

\section{The solution method}

The resulted crisp equivalent model is a BOMILP model. To solve the multi-objective models, various methods have been proposed in the literature. These methods are classified into three categories mainly priori, interactive and posteriori methods [23]. Among these methods, fuzzy interactive methods are one of the most attractive approaches in this area due to their ability measure and adjust the satisfaction level of each objective function based on the decision maker preferences in an interactive and progressive way. According to the structure of supply chain, we use three approaches mainly the weighted additive approach proposed by [24], to handle the centralized structure of supply chain as well as [25] and [26] to handle decentralized structure of Supply Chain.

The steps of the proposed fuzzy interactive method can be summarized as follows:

Step 1: Solve the model by considering a single-objective problem in respect of total costs and service level objective functions. In other words,

For total costs function:

Min $\mathrm{OF}_{1}$ Subject to constraints (8'), (9-11), (12'), (14-15), (16-20)' and (21).

For service level function:

Max $\mathrm{OF}_{2}$ Subject to constraints (8'), (9-11), (12'), (14-15), (16-20)' and (21).

Let $x$ and $x^{\prime}$ denote the optimal solutions obtained by solving the single-objective problems in respect of total costs and service level objective functions, respectively. If both the solutions, i.e., $x=x^{\prime}$ we obtain an efficient (preferred compromise) solution and stop; otherwise, go to step 3.
Step 2: Evaluate both the objective functions at the obtained solutions. Determine the $\alpha$-negative ideal solution $\left(\mathrm{OF}_{1}^{\mathrm{NIS}}\right)$ and the $\alpha$-positive ideal solution $\left(\mathrm{OF}_{1}^{\mathrm{PIS}}\right)$ for total costs objective; and, the $\alpha$-negative ideal solution $\left(\mathrm{OF}_{2}^{\mathrm{NIS}}\right)$ and the $\alpha$-positive ideal solution $\left(\mathrm{OF}_{2}^{\mathrm{PIS}}\right)$ for total lost objective as follows:

$\left\{\begin{array}{l}\mathrm{OF}_{1}^{\mathrm{NIS}}=\mathrm{OF}_{1}(\mathrm{x}) \\ \mathrm{OF}_{1}^{\mathrm{PIS}}=\mathrm{OF}_{1}\left(\mathrm{x}^{\prime}\right) \\ \mathrm{OF}_{2}^{\mathrm{PIS}}=\mathrm{OF}_{2}\left(\mathrm{x}^{\prime}\right) \\ \mathrm{OF}_{2}^{\mathrm{NIS}}=\mathrm{OF}_{2}(\mathrm{x})\end{array}\right.$

Step 3: Define the linear membership functions for total costs and service level objective functions as follows:

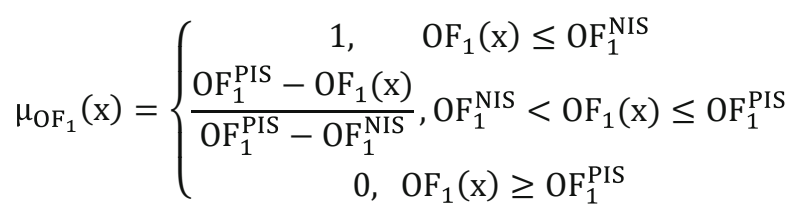

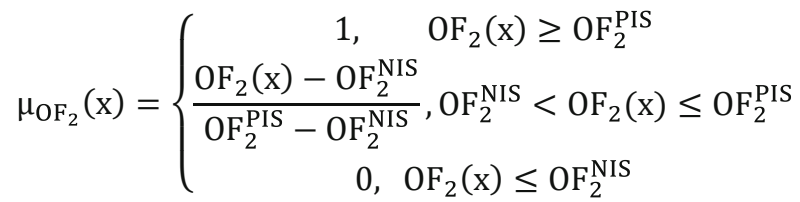

where $\mu_{\mathrm{OF}_{1}}(x)$ and $\mu_{\mathrm{OF}_{2}}(x)$ denote the satisfaction degree of total costs and service level objective functions for the given solution $x$ respectively. A graphical representation of both membership functions is presented in Figs. 2 and 3, respectively. 


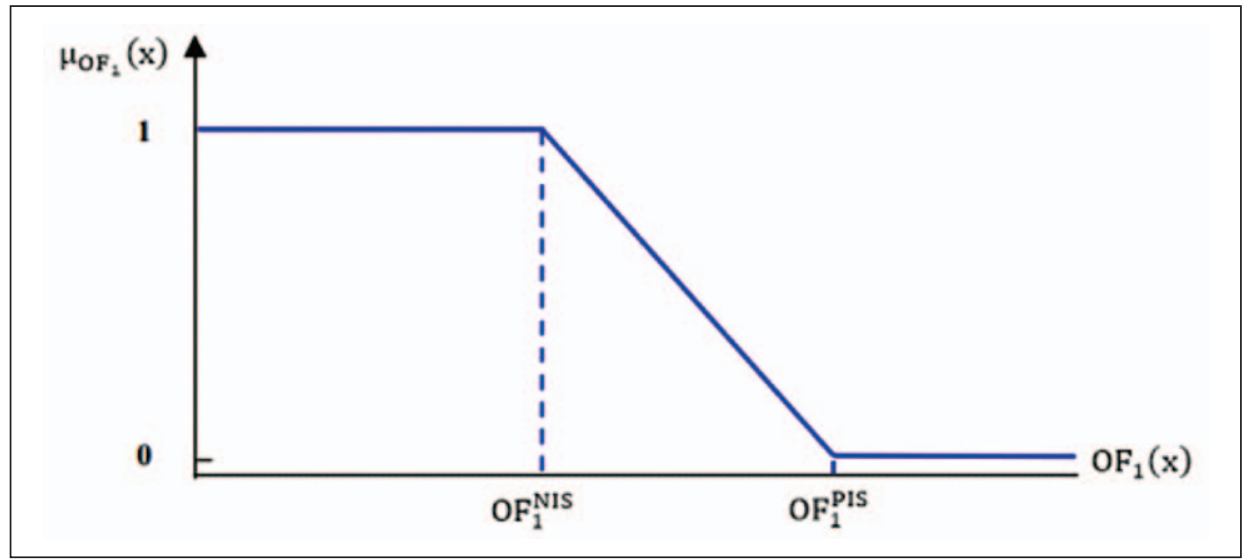

Figure 2 The membership function of the total costs' objective

Source: Authors

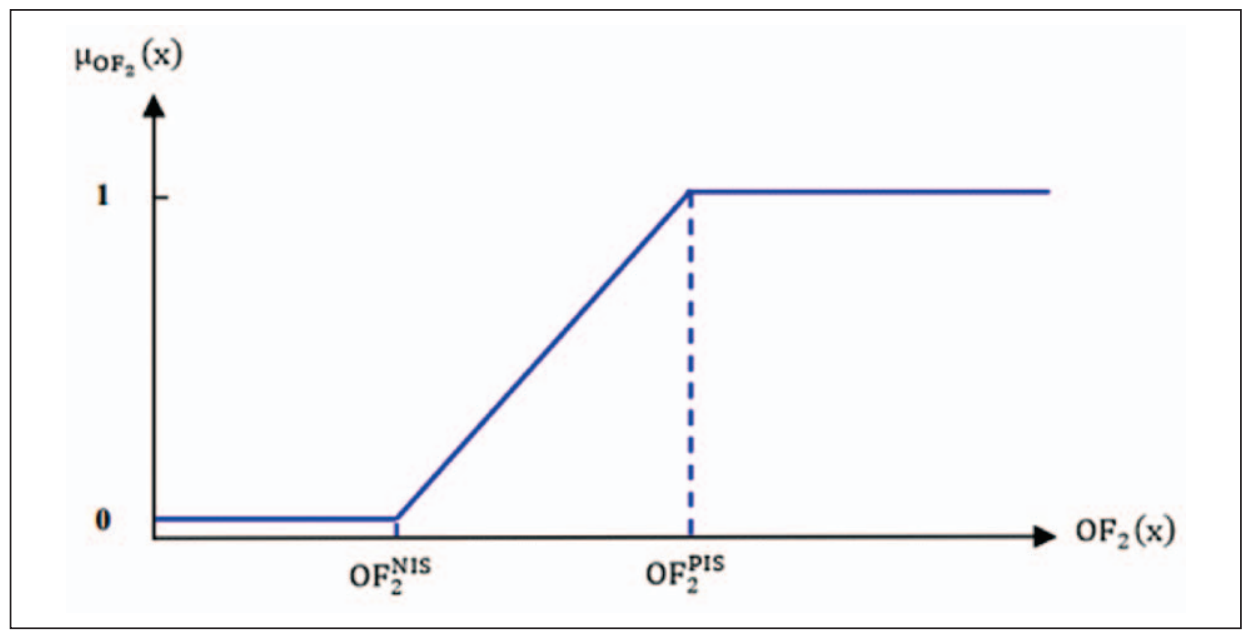

Figure 3 The membership function of the on-time deliveries

Source: Authors

Step 4: Convert the crisp equivalent model (I) + (II) into a single objective (III) function was considered both cases:

Case (a) the structure of supply chain network considered is centralized.

In order to handle the problem of centralized supply chain, [25] proposes to use [24] weighted additive approach expressed in equation 25 :

$$
\left\{\begin{array}{c}
\operatorname{Max} \sum_{\mathrm{k}} \omega_{\mathrm{k}} * \mu_{\mathrm{k}}(\mathrm{x}) \\
\text { S.t } \\
\mu_{\mathrm{k}}(\mathrm{x}) \in[0,1] \\
\mathrm{x} \geq 0
\end{array}\right.
$$

In this approach, $\omega_{k}$ and $\mu_{k}$ express the weight and the satisfaction degree of the $k^{\text {th }}$ goal respectively. Then, the weighted additive approach allows the dominant partner in the supply chain to assign different weights to the individual goals in the simple additive fuzzy achievement function to reflect their relative importance levels.

According to [24], the equivalent MILP model can be formulated as follows to solve the single model:

$$
\left\{\begin{array}{c}
\operatorname{Max} \omega_{\mathrm{OF}_{1}} * \mu_{\mathrm{OF}_{1}}(\mathrm{x})+\omega_{\mathrm{OF}_{2}} * \mu_{\mathrm{OF}_{2}}(\mathrm{x}) \\
\text { S.t } \\
\mu_{\mathrm{OF}_{1}}(\mathrm{x}), \mu_{\mathrm{OF}_{2}}(\mathrm{x}) \in[0,1] \\
\left(8^{\prime}\right),(9-11),\left(12^{\prime}\right),(14-15),(16-20)^{\prime} \\
(21)
\end{array}\right.
$$

Case (b) the structure of supply chain network considered is decentralized.

In order to handle the problem in decentralized Supply Chain, [25] extends the [27] fuzzy and operator. According to these authors, a fuzzy multi-objective model can be transformed into a single objective model as follows: 


$$
\left\{\begin{array}{c}
\operatorname{Max} \lambda(\mathrm{x})=\gamma * \lambda_{0}+(1-\gamma) * \sum_{\mathrm{k}} \theta_{\mathrm{k}} * \lambda_{\mathrm{k}}(\mathrm{x}) \\
\text { s.t } \\
\lambda_{0}+\lambda_{\mathrm{k}} \leq \mu_{\mathrm{k}}(\mathrm{x}) \mathrm{k}=1,2, \ldots, \mathrm{n} \\
\mathrm{x} \in \mathrm{F}(\mathrm{x}) \\
\lambda_{0}, \lambda_{\mathrm{k}}, \gamma \in[0,1]
\end{array}\right.
$$

Where $\mu_{k}$ and $\lambda_{0}=\min \left\{\mu_{k}(x)\right\}$ denote the degree of satisfaction corresponding to the $k^{\text {th }}$ objective function and the minimum degree of satisfaction of the objectives, respectively. Furthermore, $\lambda_{k}$ denotes the difference between each objective's level of satisfaction and the minimum level of satisfaction corresponding to the objectives $\left(\lambda_{k}=\mu_{k}-\right.$ $\left.\gamma_{0}\right)$. Moreover, $\theta_{k}$ and $\gamma$ indicate the relative importance of the $k^{\text {th }}$ objective function and the compensation coefficient, respectively. The $\theta_{k}$ parameters are determined by the decision maker based on their preferences so that $\Sigma_{k} \theta_{k}-1$; $\theta_{k}>0$.

According to [25], the equivalent MILP model can be formulated as follows to solve the single model:

$$
\left\{\begin{array}{c}
\text { Maximiser } \lambda(\mathrm{x})= \\
=\gamma * \lambda_{0}+(1-\gamma) *\left(\omega_{\mathrm{OF}_{1}} * \mu_{\mathrm{OF}_{1}}(\mathrm{x})+\omega_{\mathrm{OF}_{2}} * \mu_{\mathrm{OF}_{2}}(\mathrm{x})\right) \\
\text { s.t } \\
\lambda_{0}+\lambda_{\mathrm{OF}_{1}} \leq \mu_{\mathrm{OF}_{1}}(\mathrm{x}) \\
\lambda_{0}+\lambda_{\mathrm{OF}_{2}} \leq \mu_{\mathrm{OF}_{2}}(\mathrm{x}) \\
\omega_{\mathrm{OF}_{1}}+\omega_{\mathrm{OF}_{2}}=1 ; \\
\lambda_{0}, \lambda_{\mathrm{OF}_{1}}, \lambda_{\mathrm{OF}_{2}}, \gamma \in[0,1] \\
\left(8^{\prime}\right),(9-11),\left(12^{\prime}\right),(14-15),(16-20)^{\prime},(21)
\end{array}\right.
$$

Regarding the efficiency of the approach proposed by [25], this approach usually yields an efficient but unbalanced and poorly compromised solution so that the satisfaction degrees of objectives have considerable differences, which is often not acceptable by the decision maker [26]. To overcome this problem, [26] propose a new single-phase fuzzy approach as a combination of the previous methods of [28] and [25]. According to [26], a multi-objective model could be transformed into a single objective model as follows:

$$
\left\{\begin{array}{c}
\operatorname{Max} \lambda(\mathrm{x})=\gamma * \lambda_{0}+(1-\gamma) * \sum_{\mathrm{k}} \theta_{\mathrm{k}} * \lambda_{\mathrm{k}}(\mathrm{x}) \\
\text { s.t } \\
\lambda_{0} \leq \mu_{\mathrm{k}}(\mathrm{x}) \quad \mathrm{k}=1,2, \ldots, \mathrm{n} \\
\mathrm{x} \in \mathrm{F}(\mathrm{x}) \\
\lambda_{0}, \gamma \in[0,1]
\end{array}\right.
$$

Where $\mu_{k}$ and $\lambda_{0}=\min \left\{\mu_{k}(x)\right\}$ denote the satisfaction degree of the $k^{\text {th }}$ objective function and the minimum degree of satisfaction of objectives, respectively. Moreover, $\theta_{k}$ and $\gamma$ indicate the relative importance of the $k^{\text {th }}$ objective function and the compensation coefficient, respectively.

According to [26], the equivalent MILP model can be formulated as follows to solve the single model:

$$
\left\{\begin{array}{c}
\text { Maximiser } \lambda(\mathrm{x})= \\
=\gamma * \lambda_{0}+(1-\gamma) *\left(\underset{\mathrm{OF}_{1}}{ } * \mu_{\mathrm{OF}_{1}}(\mathrm{x})+\omega_{\mathrm{OF}_{2}} * \mu_{\mathrm{OF}_{2}}(\mathrm{x})\right) \\
\quad \mathrm{s.t} \\
\lambda_{0} \leq \mu_{\mathrm{OF}_{1}}(\mathrm{x}) \\
\lambda_{0} \leq \mu_{\mathrm{OF}_{2}}(\mathrm{x}) \\
\omega_{\mathrm{OF}_{1}}+\omega_{\mathrm{OF}_{2}}=1 ; \\
\lambda_{0}, \gamma \in[0,1] \\
\left(8^{\prime}\right),(9-11),\left(12^{\prime}\right),(14-15),(16-20)^{\prime},(21)
\end{array}\right.
$$

Step 5: Specify the importance of the objectives $\left(\omega_{\mathrm{OF} 1}\right.$, $\left.\omega_{\mathrm{OF}_{2}}\right)$ and the value of compensation coefficient $(\gamma)$ based on decision maker preferences and solve the resulting single-objective problem (26), (28) and (30). If the decision maker is satisfied with the obtained efficient solution, then stop and select the current solution as the final decision; otherwise, alter the required parameters such as $\beta$, $\omega_{\mathrm{OF}_{1} 1}, \omega_{\mathrm{OF}_{2}}$ and $\gamma$ according to the revised and updated preferences of the decision maker. Reformulate model (26), (28) and (30) and go to either Step 1 or Step 5.

\section{Computational results}

In this paper, the problem of integrating the procurement, production and distribution functions of a fourechelon supply chain network is presented, Table 2 shows the related random distribution for each parameter. In this work, the fuzzy parameters are considered as fuzzy triangular numbers $\xi=\left(\xi^{p}, \xi^{\mathrm{m}}, \xi^{\circ}\right)$ where, $\xi^{\mathrm{p}}$ is the most pessimistic, $\xi^{\mathrm{m}}$ is the most likely and $\xi^{\circ}$ is most optimistic values. These values must be estimated for each fuzzy parameter. In doing so, the method proposed by [28] is used. First, the most likely $\xi^{\mathrm{m}}$ value for each imprecise parameter is specified randomly according to the uniform distribution given in Table 3. Then, the most pessimistic $\xi^{p}$ and the most optimistic $\xi^{\circ}$ values of a fuzzy number $\xi$ are obtained as $\xi^{p}=\left(1-r_{1}\right) \xi^{m}, \xi^{o}=\left(1+r_{2}\right) \xi^{m}$ where $\left(r_{1}, r_{2}\right)$ are two numbers randomly generated according to the uniform distribution [0.1, 0.3]. The predetermined level $\theta$ is set to 0.8 . The sizes of the designed test problems are given in Table 4.

The equivalent auxiliary crisp model is coded in GAMS 22.5/CPLEX 12.2 optimization software and all numerical experiments are solved using a Core i5 $2.10 \mathrm{GHz}$ computer with 4 GB RAM. As stated previously, to deal with the centralized supply chain network structure we use the weighted additive approach proposed by [24], when we use [25] and [26] approaches to deal with the decentralized supply chain network structure. The obtained results by [24], [25] and [26] approaches are presented in Table 3 , where $\omega_{\mathrm{OF}_{1}}$ and $\omega_{\mathrm{OF}_{2}}$ denote the weights associated with total costs and on time deliveries objectives functions for each instance respectively. Both weights are set to 0.5 . The compensation coefficient is set to 0.5 . In addition, $\mu_{\mathrm{OF} 1}(x)$ and $\mu_{\mathrm{OF}_{2}}(x)$ denote the degree of satisfaction of the objective functions for the proposed method. 
Table 2 Model parameters

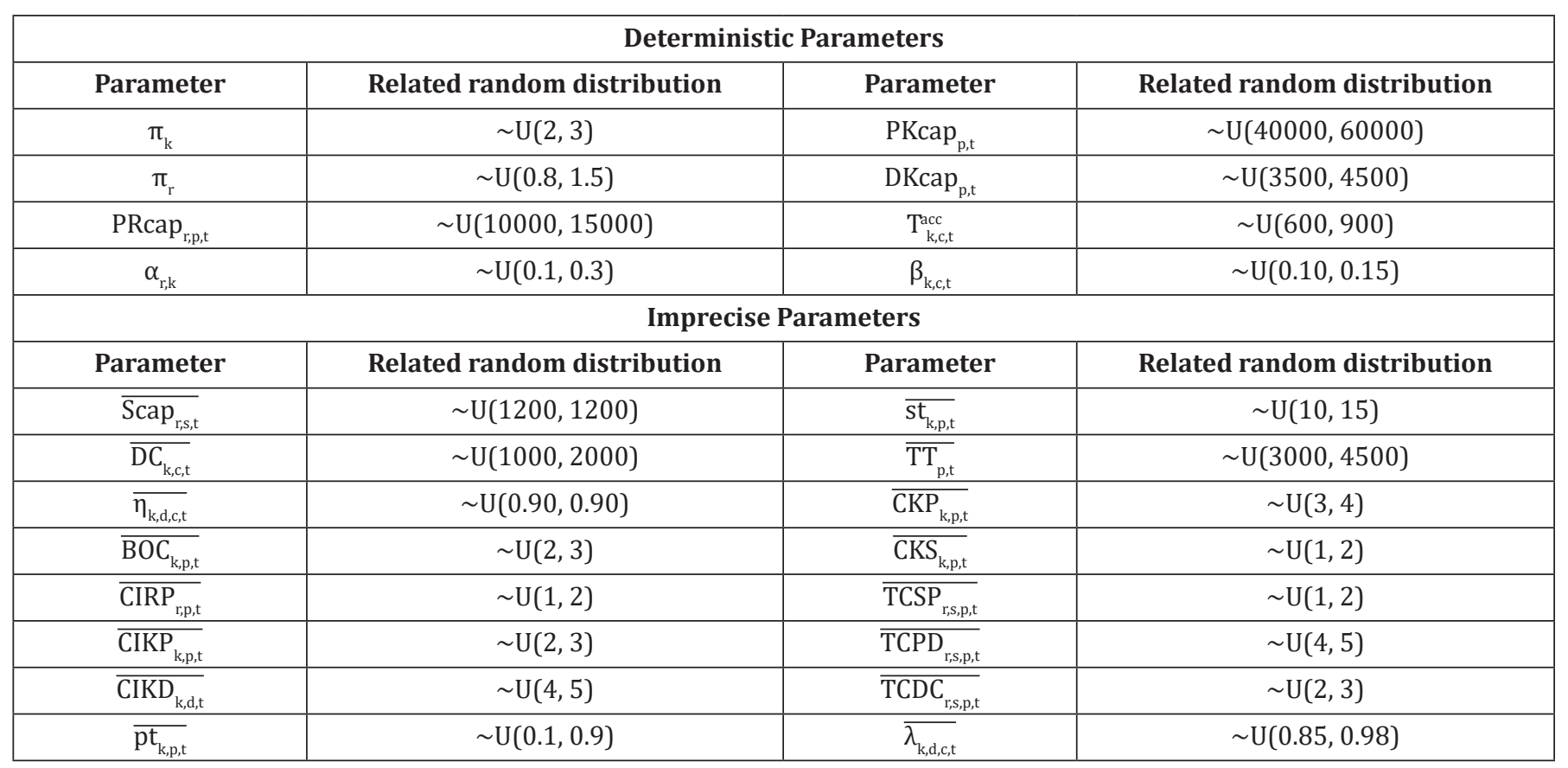

Source: Authors

Table 3 Instances problem

\begin{tabular}{|c|c|c|c|c|c|c|c|}
\hline Instance & $\begin{array}{c}\text { No. of raw } \\
\text { material }\end{array}$ & $\begin{array}{c}\text { No. of } \\
\text { supplier }\end{array}$ & $\begin{array}{l}\text { No. of } \\
\text { plant }\end{array}$ & $\begin{array}{c}\text { No. of } \\
\text { DCs }\end{array}$ & $\begin{array}{c}\text { No. of } \\
\text { customers }\end{array}$ & $\begin{array}{c}\text { No. of } \\
\text { products }\end{array}$ & $\begin{array}{l}\text { No. of } \\
\text { period }\end{array}$ \\
\hline Inst1 & 4 & 9 & 8 & 12 & 12 & 6 & 11 \\
\hline Inst3 & 4 & 12 & 8 & 5 & 9 & 5 & 7 \\
\hline Inst4 & 5 & 6 & 8 & 8 & 4 & 4 & 7 \\
\hline Inst7 & 5 & 15 & 12 & 8 & 9 & 5 & 11 \\
\hline Inst8 & 6 & 9 & 5 & 5 & 12 & 4 & 15 \\
\hline Inst9 & 6 & 9 & 12 & 12 & 6 & 5 & 9 \\
\hline Inst10 & 6 & 12 & 12 & 12 & 9 & 4 & 11 \\
\hline
\end{tabular}

Source: Authors

Table 4 Sensitivity analysis of supplier capacity and on-time delivery rate impact

\begin{tabular}{|c|c|c|c|c|}
\hline On-time delivery rate - Supplier capacity & $\mathbf{1 2 0 0}$ & $\mathbf{1 4 0 0}$ & $\mathbf{1 6 0 0}$ & $\mathbf{1 8 0 0}$ \\
\hline 0,4 & 141606 & 162466 & 182501 & 202354 \\
\hline 0,5 & 177008 & 203083 & 228126 & 252942 \\
\hline 0,6 & 212410 & 243700 & 273751 & 303531 \\
\hline 0,7 & 247811 & 284317 & 319377 & 354120 \\
\hline 0,8 & 283213 & 324933 & 365002 & 404708 \\
\hline 0,9 & 318615 & 365550 & 410627 & 455297 \\
\hline
\end{tabular}




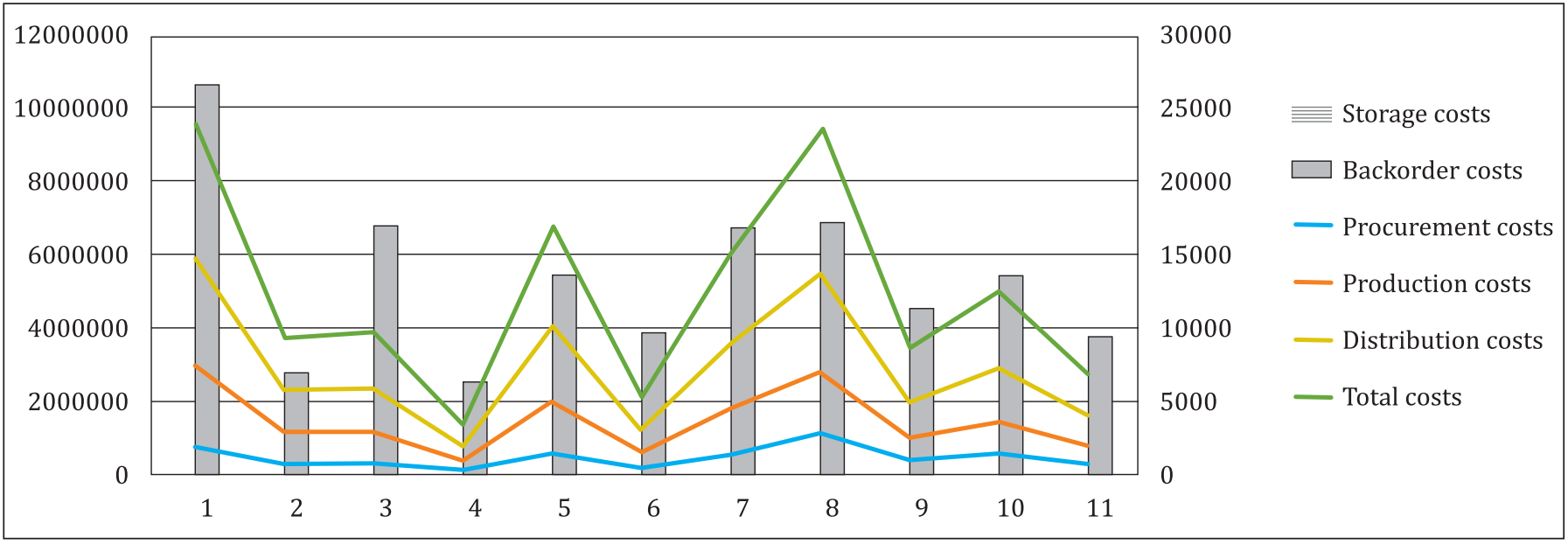

Figure 4 Distribution of all costs for all considered instances

Source: Authors

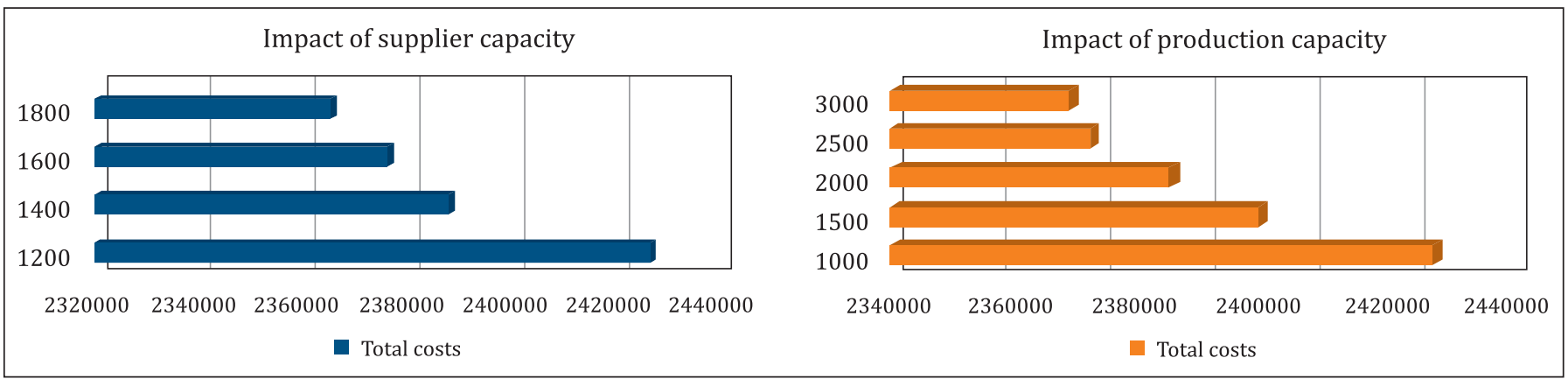

Figure 5 Sensitivity analysis of supplier and production capacity impact

Source: Authors

It follows from the figure 4 that the storage costs including (storage in plants and DCs) are equal to zero due to the fact of the favour of the distribution (distribution costs represent the highest value in the graph) rather than storage to satisfy the customer demand which verified by the backlog costs which are very small rather than production or distribution costs.

In addition, we carried out sensitivity analysis to investigate the impact of some input parameters on the value of both objective functions. Table 4 represents the impact of on-time delivery provided by suppliers as well as the supplier capacity on values of the second objective. It follows from figure 5 that the quantities of raw materials delivered on time increase as both parameters increase. As a decision we consider the highest weight to these criteria when selecting suppliers. To explore the influence of different weight structures on the results of the problem several problem instances of weights are generated for instance problem No 11.

Table 5 Solution results obtained by [24] approach for centralized structure

\begin{tabular}{|c|c|c|c|c|c|}
\cline { 2 - 6 } \multicolumn{1}{c|}{} & $\mathbf{1}$ & $\mathbf{2}$ & $\mathbf{3}$ & $\mathbf{4}$ & $\mathbf{5}$ \\
\hline$\omega_{\mathrm{OF}_{1}}$ & 0.1 & 0.3 & 0.5 & 0.7 & 0.9 \\
\hline$\omega_{\mathrm{OF}_{2}}$ & 0.9 & 0.7 & 0.5 & 0.3 & 0.1 \\
\hline$\mu_{\mathrm{OF}_{1}}(\mathrm{x})$ & 0.79 & 0.93 & 0.89 & 0.94 & 0.99 \\
\hline$\mu_{\mathrm{OF}_{2}}(\mathrm{x})$ & 1.00 & 0.98 & 0.97 & 0.95 & 0.64 \\
\hline
\end{tabular}

Source: Authors

Table 6 Solution results obtained by [25] and [26] approaches for decentralized structure

\begin{tabular}{|c|c|c|c|c|c|c|c|c|}
\hline & \multicolumn{8}{|c|}{$\gamma$} \\
\hline & & 0.0 & 0.1 & 0.3 & 0.5 & 0.7 & 0.9 & 1 \\
\hline \multirow{2}{*}{ SO } & $\mu_{\mathrm{OF}_{1}}(\mathrm{x})$ & 0.96 & 0.95 & 0.93 & 0.92 & 0.92 & 0.91 & 0.89 \\
\hline & $\mu_{\mathrm{OF}_{2}}(\mathrm{x})$ & 1.00 & 0.98 & 0.97 & 0.97 & 0.97 & 0.95 & 0.96 \\
\hline \multirow{2}{*}{ TH } & $\mu_{\mathrm{OF}_{1}}(\mathrm{x})$ & 0.91 & 0.91 & 0.91 & 0.91 & 0.91 & 0.92 & 0.92 \\
\hline & $\mu_{\mathrm{OF}_{2}}(\mathrm{x})$ & 1.00 & 1.00 & 0.99 & 0.99 & 0.99 & 0.99 & 0.99 \\
\hline
\end{tabular}

Source: Authors 
It can be seen from Table 5 that the degree of satisfaction of each objective function decrease as the increase of its weight for [24] approach.

It can be seen from Table 4 and Figure 5 that the method proposed by [25] is sensitive to the compensa- tion coefficient so that it produces different unbalanced solutions. On the other hand, the [26] method is not very sensitive to value so that it produces appropriately an efficient solution. The optimal solutions are presented in Tables 7-9.

Table 7 Produced quantity of finished products in plants

\begin{tabular}{|c|c|c|c|c|c|c|c|c|}
\hline & & t1 & t2 & t3 & t4 & t5 & t6 & t7 \\
\hline \multirow[b]{2}{*}{ k1 } & p1 & 9365,38 & - & 4961,85 & 6883,25 & 1344,35 & - & - \\
\hline & p2 & - & - & - & - & - & - & 9512,19 \\
\hline \multirow{5}{*}{ k2 } & p1 & 1094,35 & - & 5093,53 & 1735,12 & 6481,43 & 8575,61 & 7250,55 \\
\hline & p2 & - & - & - & 3166,06 & - & 6335,55 & - \\
\hline & p4 & 5047,12 & - & - & 1236,22 & - & - & - \\
\hline & p5 & - & 154,55 & - & - & - & - & - \\
\hline & p7 & - & - & 2657,79 & - & - & 5697,79 & 12137,57 \\
\hline \multirow{2}{*}{ k3 } & p1 & - & - & - & 1485,95 & - & - & - \\
\hline & p2 & 9050,93 & - & - & - & - & 4931,57 & 5103,52 \\
\hline \multirow{7}{*}{ k4 } & p1 & 5515,76 & - & - & 5374,87 & - & - & - \\
\hline & p2 & 354,39 & - & - & - & 6523,54 & - & - \\
\hline & p3 & - & & 1119,41 & - & & & \\
\hline & p4 & - & & - & - & 2478,87 & - & - \\
\hline & p5 & - & 1329,03 & - & - & - & - & - \\
\hline & p6 & - & 2581,02 & - & - & - & - & - \\
\hline & p8 & - & & 6112,13 & - & - & - & - \\
\hline
\end{tabular}

Source: Authors

Table 8 Quantity of inventory of raw materials in plant

\begin{tabular}{|c|c|c|c|c|c|c|c|c|}
\hline & & t1 & t2 & t3 & t4 & t5 & t6 & t7 \\
\hline \multirow{6}{*}{ rm1 } & p1 & 2439,28 & 2439,28 & & 5555,31 & 3521,00 & 1212,26 & 8283,28 \\
\hline & p2 & 6366,30 & 16682,74 & 16682,74 & 18704,67 & 17610,12 & 14477,40 & 22729,87 \\
\hline & p4 & - & 1790,27 & - & 415,92 & - & - & 1535,15 \\
\hline & p5 & 2707,41 & 2411,17 & 2411,17 & - & - & - & 4589,89 \\
\hline & p7 & 715,54 & 715,54 & - & - & - & - & - \\
\hline & p8 & 1025,53 & 1025,53 & - & - & - & - & - \\
\hline \multirow{4}{*}{$\mathrm{rm} 2$} & p1 & - & - & 14150,60 & 11642,42 & 10404,40 & 9024,39 & 7857,62 \\
\hline & p2 & 4530,41 & 4530,41 & 5304,28 & 4794,79 & 3498,96 & 1939,05 & - \\
\hline & p3 & & 1144,14 & 921,78 & 921,78 & 921,78 & 921,78 & 921,78 \\
\hline & p7 & - & 427,70 & - & - & 830,48 & 1953,21 & - \\
\hline
\end{tabular}




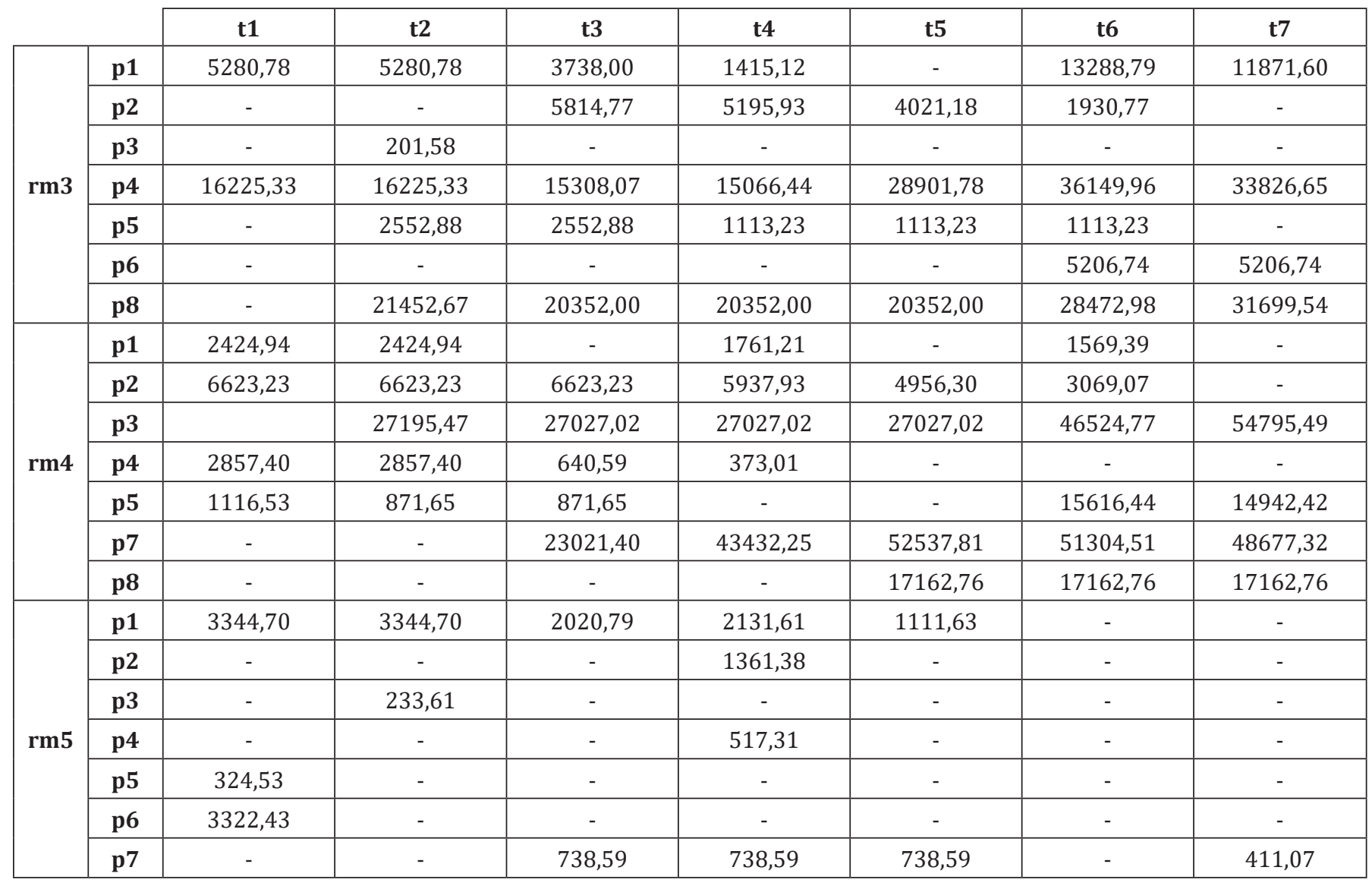

Source: Authors

Table 9 Quantity of inventory of finished products in plants

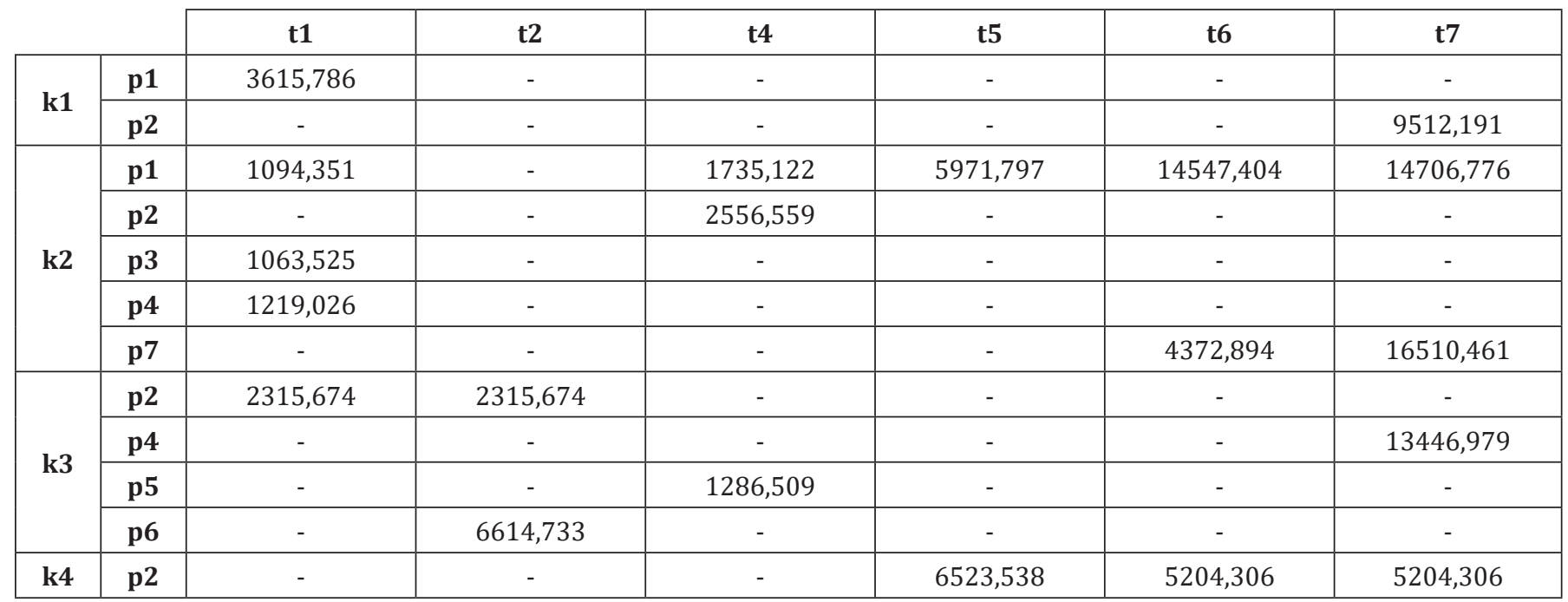

Source: Authors 
Table 10 Quantity of inventory of finished products in DCs

\begin{tabular}{|c|c|c|c|c|c|c|c|c|}
\hline & & t1 & t2 & t3 & t4 & t5 & t6 & t7 \\
\hline \multirow{3}{*}{ k1 } & d2 & 2181,23 & 1169,45 & - & - & - & - & - \\
\hline & d6 & - & - & 2261,41 & 74,28 & 1186,48 & - & - \\
\hline & d7 & - & - & 7063,44 & 4961,34 & 2427,46 & - & - \\
\hline \multirow{3}{*}{ k2 } & d1 & - & - & 1500,41 & - & - & 5033,42 & 2344,92 \\
\hline & d3 & 1346,09 & - & - & - & - & - & 5747,90 \\
\hline & d6 & - & - & 1314,91 & - & - & - & - \\
\hline \multirow{3}{*}{ k3 } & d1 & - & 2280,36 & - & - & 1286,51 & - & 5272,05 \\
\hline & d7 & - & - & 1006,17 & - & - & - & - \\
\hline & d8 & - & - & 1179,05 & - & - & - & - \\
\hline \multirow{3}{*}{ k4 } & d1 & - & - & - & 3276,37 & - & 1319,23 & - \\
\hline & d3 & 1240,28 & - & - & - & - & - & - \\
\hline & d8 & - & - & 2475,24 & - & 2478,87 & - & - \\
\hline
\end{tabular}

Source: Authors

\section{Conclusion}

In this paper, we devoted the integration problem of procurement, production and distribution of a supply chain network under uncertainty within the credibility framework. The proposed model is a bi-objective mixed integer linear programming which considers technological constraints arising in many kinds of supply chain network and aims to minimize the total costs such as production, storage, and distribution as well as to maximize the ontime deliveries in order to ensure a continuous flow of production and to minimize line stoppages in plants due to unavailability of raw materials items. To bring the model closer to real-world planning problems, the objective function coefficients (e.g. production costs, inventory holding and transport costs) and other parameters (e.g., demand, and production capacity), are all considered fuzzy numbers. To overcome the problems related to use single model such as expected value model or chance-constrained model. To transform the bi-objective model, we used the aggregate functions to handle each structure mainly [24], [25] and [26]. Finally, reported numerical results showing the practicality of the proposed model.

The proposed model considered the fuzziness as the source of uncertainty. However, a future research could be aimed at addressing hybrid uncertainties, such as an encounter with fuzziness and roughness simultaneously. For example, it is widely accepted that the demand of the customer is presented as a triangular fuzzy number $(a, b$, c) variable from the viewpoint of the fuzzy theory, but the values of $a, b$ and $c$ may emerge with incomplete or uncertain information. In a sense, the values of $\mathrm{a}, \mathrm{b}$ and $\mathrm{c}$ are of rough characteristics. Thus, the decision-makers have to face the fuzzy number of rough parameters. In this case, the clients demand should be more appropriately represented as the so-called fuzzy rough variable [16].

Funding: The research presented in the manuscript did not receive any external funding.

Acknowledgments: The authors would like to thank EL MHAMDI Oussama for providing language help during the writing of this paper.

Author Contributions: Kaoutar Douaioui: conceptualization, formal analyzes, original draftand Investigation Mouhsene Fri: Conceptualization, methodology, review and editing. Charif Mabrouki: review, editing, supervision and validation. El Alami Semma: supervision and final approval.

\section{References}

[1] W. Klibi, A. Martel, and A. Guitouni, "The design of robust value-creating supply chain networks: A critical review," European Journal of Operational Research, vol. 203, no. 2, pp. 283-293, Jun. 2010, doi: 10.1016/j.ejor.2009.06.011. 
[2] J. Kim, B. Do Chung, Y. Kang, and B. Jeong, "Robust optimization model for closed-loop supply chain planning under reverse logistics flow and demand uncertainty," Journal of cleaner production, vol. 196, pp. 1314-1328, 2018.

[3] M. Zheng, L. Zhang, Y. Feng, L. He, and G. Sun, "Credibilitybased fuzziness and incomplete information value in fuzzy programming," Evol. Intel., Aug. 2020, doi: 10.1007/s12065020-00467-9.

[4] A. Giallanza and G. L. Puma, "Fuzzy green vehicle routing problem for designing a three echelons supply chain," Journal of Cleaner Production, p. 120774, 2020.

[5] K. Govindan, M. Fattahi, and E. Keyvanshokooh, "Supply chain network design under uncertainty: A comprehensive review and future research directions," European Journal of Operational Research, vol. 263, no. 1, pp. 108-141, 2017.

[6] M. Talaei, B. Farhang Moghaddam, M. S. Pishvaee, A. Bozorgi-Amiri, and S. Gholamnejad, "A robust fuzzy optimization model for carbon-efficient closed-loop supply chain network design problem: a numerical illustration in electronics industry," Journal of Cleaner Production, vol. 113, pp. 662-673, Feb. 2016, doi: 10.1016/j.jclepro.2015.10.074.

[7] H. Soleimani, K. Govindan, H. Saghafi, and H. Jafari, "Fuzzy multi-objective sustainable and green closed-loop supply chain network design," Computers \& industrial engineering, vol. 109, pp. 191-203, 2017.

[8] H. Lu, P. Du, Y. Chen, and L. He, "A credibility-based chanceconstrained optimization model for integrated agricultural and water resources management: a case study in South Central China," Journal of Hydrology, vol. 537, pp. 408-418, 2016.

[9] M. Abdel-Basset, R. Mohamed, K. Sallam, and M. Elhoseny, "A novel decision-making model for sustainable supply chain finance under uncertainty environment," Journal of Cleaner Production, p. 122324, 2020.

[10] S. Prakash, S. Kumar, G. Soni, V. Jain, and A. P. S. Rathore, "Closed-loop supply chain network design and modelling under risks and demand uncertainty: an integrated robust optimization approach," Annals of Operations Research, vol. 290, no. 1, pp. 837-864, 2020.

[11] M. Fazli-Khalaf, A. Mirzazadeh, and M. S. Pishvaee, "A robust fuzzy stochastic programming model for the design of a reliable green closed-loop supply chain network," Human and Ecological Risk Assessment: An International Journal, vol. 23, no. 8, pp. 2119-2149, 2017.

[12] Q. Rong, Y. Cai, B. Chen, W. Yue, X. Yin, and Q. Tan, "An enhanced export coefficient based optimization model for supporting agricultural nonpoint source pollution mitigation under uncertainty," Science of The Total Environment, vol. 580, pp. 1351-1362, Feb. 2017, doi: 10.1016/j.scitotenv.2016.12.099.

[13] M. S. Pishvaee and S. A. Torabi, "A possibilistic programming approach for closed-loop supply chain network design under uncertainty," Fuzzy Sets and Systems, vol. 161, no. 20, pp. 2668-2683, Oct. 2010, doi: 10.1016/j.fss.2010.04.010.

[14] S.-T. Liu and C. Kao, "Solving fuzzy transportation problems based on extension principle," European Journal of
Operational Research, vol. 153, no. 3, pp. 661-674, Mar. 2004, doi: 10.1016/S0377-2217(02)00731-2.

[15] D. Dubois, L. Foulloy, G. Mauris, and H. Prade, "ProbabilityPossibility Transformations, Triangular Fuzzy Sets, and Probabilistic Inequalities," Reliable Computing, vol. 10, no. 4, pp. 273-297, Aug. 2004, doi: 10.1023/B:REOM.0000032115. 22510.b5.

[16] Baoding Liu and Yian-Kui Liu, "Expected value of fuzzy variable and fuzzy expected value models," IEEE Transactions on Fuzzy Systems, vol. 10, no. 4, pp. 445-450, Aug. 2002, doi: 10.1109/TFUZZ.2002.800692.

[17] X. Huang, "Credibility-based chance-constrained integer programming models for capital budgeting with fuzzy parameters," Information Sciences, vol. 176, no. 18, pp. 2698-2712, Sep. 2006, doi: 10.1016/j.ins.2005.11.012.

[18] M. S. Pishvaee, S. A. Torabi, and J. Razmi, "Credibility-based fuzzy mathematical programming model for green logistics design under uncertainty," Computers \& Industrial Engineering, vol. 62, no. 2, pp. 624-632, Mar. 2012, doi: 10.1016/j.cie.2011.11.028.

[19] H. Zhu and J. Zhang, "A Credibility-Based Fuzzy Programming Model for APP Problem," in 2009 International Conference on Artificial Intelligence and Computational Intelligence, Nov. 2009, vol. 1, pp. 455-459, doi: 10.1109/AICI.2009.204.

[20] Baoding Liu and Kakuzo Iwamura, "A note on chance constrained programming with fuzzy coefficients," Fuzzy Sets and Systems, vol. 100, no. 1-3, pp. 229-233, Nov. 1998, doi: 10.1016/S0165-0114(97)00291-1.

[21] Boading Liu, "Dependent-chance programming with fuzzy decisions," IEEE Trans. Fuzzy Syst., vol. 7, no. 3, pp. 354-360, Jun. 1999, doi: 10.1109/91.771090.

[22] S.-T. Liu, "A revisit to quadratic programming with fuzzy parameters," Chaos, Solitons \& Fractals, vol. 41, no. 3, pp. 1401-1407, Aug. 2009, doi: 10.1016/j.chaos.2008.04.061.

[23] C.-L. Hwang and A. S. Md. Masud, Multiple Objective Decision Making - Methods and Applications, vol. 164. Berlin, Heidelberg: Springer Berlin Heidelberg, 1979.

[24] R. Tiwari, S. Dharmar, and J. Rao, "Fuzzy goal programming-an additive model," Fuzzy sets and systems, vol. 24, no. 1, pp. 27-34, 1987.

[25] H. Selim and I. Ozkarahan, "A supply chain distribution network design model: an interactive fuzzy goal programming-based solution approach," The International Journal of Advanced Manufacturing Technology, vol. 36, no. 3-4, pp. 401-418, 2008.

[26] S. A. Torabi and E. Hassini, "An interactive possibilistic programming approach for multiple objective supply chain master planning," Fuzzy Sets and Systems, vol. 159, no. 2, pp. 193-214, 2008, doi: https://doi.org/10.1016/j. fss.2007.08.010.

[27] B. M. Werners, "Aggregation models in mathematical programming," in Mathematical models for decision support, Springer, pp. 295-305, 1988.

[28] Y.-J. Lai and C.-L. Hwang, "Possibilistic linear programming for managing interest rate risk," Fuzzy Sets and Systems, vol. 54, no. 2, pp. 135-146, Mar. 1993, doi: 10.1016/01650114(93)90271-I. 